Editorial

\title{
Biomass Chars: Elaboration, Characterization and Applications II
}

\author{
Mejdi Jeguirim * (1) and Lionel Limousy \\ Université de Strasbourg, Université de Haute Alsace, Institut de Science des Matériaux de Mulhouse (IS2M) \\ UMR CNRS 7361, 68093 Mulhouse, France; lionel.limousy@uha.fr \\ * Correspondence: mejdi.jeguirim@uha.fr
}

Received: 14 November 2018; Accepted: 23 January 2019; Published: 25 January 2019

check for updates

This Special Issue of Energies contains the successful invited submissions [1-21] on the subject area of "Biomass Chars: Elaboration, Characterization and Applications". After the organization of a first edition, the guest editors have decided to continue focusing on char production from biomass and their applications various applications. In response to our call for papers we received 27 submissions, of which 21 have been published and six rejected during the peer review process. The geographical distribution of the authors of the published papers is as follows:

- China (5)

- $\operatorname{UK}(1)$

- $\quad$ France (4)

- Greece (1)

- $\quad$ Spain (1)

- $\quad$ Korea (6)

- Germany (1)

- Tunisia (1)

- $\quad$ Poland (1)

Published submissions are related to biomass char production methods, including pyrolysis, and hydrothermal carbonization. In addition, various characterization techniques were used to identify the physico-chemical, morphological, textural, surface chemistry and structural properties of the products. The main applied techniques were thermogravimetric analysis (TGA), calorimetry, $\mathrm{pH}$ measurements, scanning electron microscopy (SEM)-energy dispersive X-ray (EDX) analyses, X-ray diffraction (XRD), nitrogen gas adsorption, Fourier transform infrared spectroscopy (FTIR), etc. The different recovery routes of biomass-derived chars were also addressed. Particular attention was paid to char gasification and combustion as well as to the applications of chars for gas storage and soil amendment. The main results are described below. New developments are still under progress, encouraging the organization of a third edition of this special issue.

Moulogianni and Bournaris have ranked the agro-energy regions in the Region of Central Macedonia (RCM) according to their biomass production potential [1]. In this context, the authors have developed a Multi-Criteria Analysis (MCDA) model using the ELimination and Et Choix Traduisant la REalite (ELECTRE) III method through the construction of outranking relations. The authors concluded that agro-energy regions with cereals and arable crops will have better results than regions with fruit trees and other crops.

Khiari and Jeguirim have attempted to identify an environmentally friendly valorization method for the huge amounts of grape marc generated in Tunisia by the wine industry [2]. Hence, the authors have determined physico-chemical and energy characteristics of grape marc according to international 
standards. Based on these characteristics, they proposed a pyrolysis process as a recovery route for the grape marc due to its high minerals content and the ability to create high added value derived products. During the thermogravimetric analysis the biochar yield was about $40 \%$, a value never previously reported in the literature for an agricultural biomass subjected to slow pyrolysis. Such behavior may be attributed to the high lignin and high minerals contents in grape marc, confirming its potential for agricultural applications.

Lee et al. have studied an alternative for the recovery of food waste compost since the amount generated every day is higher than the amount consumed in farms [3]. Hence, authors have suggested producing biochar from food waste compost using pyrolysis processes. In this context, they have analyzed the thermal degradation behavior, calorific value, and char composition (using gas chromatography) during the pyrolysis of food waste compost. The authors showed that biochar from the pyrolysis of food waste compost had a high carbon content of $51 \%$ at $300{ }^{\circ} \mathrm{C}$. Hence, it seems that food waste compost can be used as a promising alternative fuel at a low pyrolysis temperature, like other lignocellulosic refuse-derived fuels (RDF)

Liu et al have studied the pyrolysis of rice straw in a horizontal tube reactor at temperatures ranging from 500 to $900{ }^{\circ} \mathrm{C}$ [4]. The authors have monitored the gaseous nitrogen components emitted during rice straw pyrolysis in order to identify the release mechanism of fuel-N into $\mathrm{NO}_{\mathrm{x}}$ and $\mathrm{N}_{2} \mathrm{O}$ precursors. A high dependency between the gaseous products and temperature was found. $\mathrm{NH}_{3}$ and $\mathrm{HNCO}$ were preferentially formed at lower temperatures and $\mathrm{HCN}$ tended to form at higher temperatures. The authors have also noted that $\mathrm{NO}$ was also an important product and its formation during the pyrolysis of rice straw was due to the direct oxidization reaction of $-\mathrm{NH}$ and $-\mathrm{OH}$, the latter being abundant in the raw material.

Hydrothermal carbonization (HTC) is an emerging technology used for bioenergy conversion from bio-wastes such as sewage sludge, livestock manure, and food waste. Oh and Yoon have studied the hydrothermal carbonization of poultry slaughterhouse sludge cake in a pilot-scale HTC reactor at temperatures from 170 to $220^{\circ} \mathrm{C}$ [5]. The authors have analyzed the gross energy recovery efficiency based on the calorific value of the HTC-biochar and the ultimate methane potential of the HTC-hydrolysate, indicating that poultry slaughterhouse sludge cake is a useful source for bioenergy conversion with a total gross energy recovery $\left(\mathrm{GER}_{\text {total }}\right)$ of $4318 \mathrm{MJ} / \mathrm{kg}$ attained at $180{ }^{\circ} \mathrm{C}$.

Similar analysis were performed by Liu et al. during the hydrothermal carbonization of a major energy crop, reeds [6]. The HTC experiments were performed in a batch reactor at $200-280{ }^{\circ} \mathrm{C}$ for 0.5 to $4 \mathrm{~h}$. The authors indicated that the hydrochar mass yield changed from $66.7 \%$ to $19.2 \%$ and high heating value (HHV) from $20.0 \mathrm{~kJ} / \mathrm{g}$ to $28.3 \mathrm{~kJ} / \mathrm{g}$, respectively, by increasing the carbonization temperature from $200{ }^{\circ} \mathrm{C}$ to $280^{\circ} \mathrm{C}$ and decreasing the residence time from $2 \mathrm{~h}$ to $1 \mathrm{~h}$.

The operating conditions in pyrolysis and hydrothermal carbonization strongly impact the properties of biochars and hydrochars. Dieguez-Alonso et al. have used pine wood (PW) and corn digestate (CD) as feedstocks for biochar and hydrochar production [7]. CD biochars showed lower $\mathrm{H} / \mathrm{C}$ ratios, thermal recalcitrance and total specific surface area than PW biochars, but higher mesoporosity. CD and PW biochars presented higher naphthalene and phenanthrene contents, respectively, which may indicate different reaction pathways. High temperatures $\left(>500{ }^{\circ} \mathrm{C}\right)$ lead to lower polycyclic aromatic hydrocarbon $(\mathrm{PAH})$ content $(<12 \mathrm{mg} / \mathrm{kg})$ and higher specific surface area. In hydrochars the high inorganic content favors decarboxylation over dehydration reactions. Hydrochars showed mainly mesoporosity, with a higher pore volume but generally lower specific surface area than biochars. Biochars presented negligible availability of $\mathrm{NO}_{3}{ }^{-}$and $\mathrm{NH}_{4}{ }^{+}$, irrespective of the nitrogen content of the feedstock. For hydrochars, a potential increase in availability of $\mathrm{NO}_{3}{ }^{-}$, $\mathrm{NH}_{4}{ }^{+}, \mathrm{PO}_{4}{ }^{3-}$, and $\mathrm{K}^{+}$with respect to the feedstock is possible.

The char characterization is a crucial step to identify the suitable recovery route for biochar. Lee et al. have analyzed the chemical characteristics of biochar produced using food waste containing low- and high-concentration salt and biochar flushed with water to remove the concentrated salt [8]. Peak analysis of XRD confirmed that it is difficult to find salt crystals in flushed char since salt remains 
in the form of crystals when salty food waste was pyrolyzed was washed away after water flushing. In addition, the $\mathrm{Cl}$ content significantly decreased to $1-2 \%$ after flushing, similar to that of $\mathrm{Cl}$ content in the standard, non-salted food waste char. On the other hand, a significant amount of Na was found in pyrolyzed char even after flushing resulting from a phenomenon in which salt is dissolved in water while flushing and $\mathrm{Na}$ ions are adsorbed. FT-IR analysis showed that salt in waste affects the binding of aromatic carbons to compounds in the pyrolysis process. NMR spectroscopy experiments demonstrated that the aromatic carbon content, which is an indicator of the stability of a biochar, is not influenced by the salt content and increases with increasing pyrolysis temperature.

Lee et al. have followed up on their investigation by analyzing food-waste-derived biochar structures obtained through pyrolysis and with different $\mathrm{NaCl}$ concentrations [9]. The authors indicate that increased $\mathrm{NaCl}$ concentration in the samples inhibited cellulose and lignin decomposition, ultimately increasing the biochar yield by $2.7 \%$ for $20 \%-\mathrm{NaCl}$ concentration. $\mathrm{NaCl}$ added in solution state exhibited templating effects, with maximum increase in the Brunauer-Emmett-Teller (BET) surface area and pore volume of 1.23 to $3.50 \mathrm{~m}^{2} \cdot \mathrm{g}^{-1}$ and 0.002 to $0.007 \mathrm{~cm}^{3} \cdot \mathrm{g}^{-1}$, respectively, after washing. Adding a high concentration $(20 \%)$ of $\mathrm{NaCl}$ reduced the BET surface area. In contrast, the mean pore diameter increased owing to the increased $\mathrm{NaCl}$ clustering area.

Different recovery routes for biomass-derived chars were examined in the literature such as combustion, gasification, pollutants adsorption, soil amendments. Boukaous et al. have examined the combustion characteristics of flax shives, beech wood, hemicellulose, cellulose, lignin, and their chars prepared in a fixed-bed reactor at $850^{\circ} \mathrm{C}$ [10]. The authors have assessed the thermal behavior based on characteristic temperatures (ignition, maximum, and final temperatures), burnout time and maximum rate. The results revealed that the combustion of pure pseudo-components behaved differently from that of biomass. In contrast, the combustion of the hemicellulose and cellulose chars showed that they have almost the same structure. Their overall thermal and kinetic behavior remained between that of biomass and lignin.

Mami et al. have carried out combustion tests of olive mill solid wastes pellets (olive pomace (OP), and olive pits (OPi)) in an updraft counter-current fixed bed reactor [11]. The authors have found that the exhaust gases were emitted in acceptable concentrations compared to the combustion of standard wood pellets reported in the literature (EN 303-5). Furthermore, it was shown that the bed temperature increased from the ambient value to a maximum value ranging from 750 to $1000{ }^{\circ} \mathrm{C}$ as previously reported in the literature. The results demonstrated the interest of using olive mill solid waste pellets as an alternative biofuel for heat and/or electricity production

Kim et al. have examined experimentally the effect of oxygen-enriched air on char combustion [12]. During their investigation, a coal-heating reactor equipped with a platinum wire mesh in the reaction chamber was used to analyze the combustion temperature, reaction time, and reaction kinetics. The authors have found that increasing the oxygen content of the primary combustion air increased the combustion temperature and decreased the reaction time. As the oxygen content increased from $21 \%$ to $30 \%$, the average temperature increased by $47.72 \mathrm{~K}$ at a setup temperature of $1673 \mathrm{~K}$, and the reaction time decreased by $30.22 \%$ at the same temperature. The graphite sample exhibited similar trends in temperature and reaction time, although the degree of change was smaller because the pores produced during char devolatilization expanded the active surface available for oxidation of the char sample. A mathematical model was used to define the intrinsic kinetics of the reaction. As the oxygen content increased from $21 \%$ to $30 \%$, the reaction rate of the low-rank coal char increased. These results were also compared with those of the graphite sample

Char gasification is attracting nowadays growing interest. Liu et al. have studied the char gasification of two coals (i.e., Shenfu bituminous coal and Zunyi anthracite) and a petroleum coke under a steam and $\mathrm{CO}_{2}$ mixture (steam $/ \mathrm{CO}_{2}$ partial pressures, $0.025-0.075 \mathrm{MPa}$; total pressures, $0.100 \mathrm{MPa}$ ) and $\mathrm{CO}_{2}$ /steam chemisorption of char samples using a Thermogravimetric Analyzer (TGA) [13]. As a result a modified model based on Langmuir-Hinshelwood model and assuming that char- $\mathrm{CO}_{2}$ and char-steam reactions partially shared active sites was proposed and had indicated 
high accuracy for estimating the interactions in char-steam- $\mathrm{CO}_{2}$ reaction. Moreover, it was found that two new model parameters (respectively characterized as the amount ratio of shared active sites to total active sites in char- $\mathrm{CO}_{2}$ and char-steam reactions) in the modified model hardly varied with gasification conditions, and the results of chemisorption indicate that these two new model parameters mainly depended on the carbon active sites in char samples

The char gasification reactivity is strongly affected by the presence of inorganic elements in the raw biomass. Feng et al. have examined the effect of chemical speciation $\left(\mathrm{H}_{2} \mathrm{O} / \mathrm{NH}_{4} \mathrm{Ac} / \mathrm{HCl}\right.$-soluble and insoluble) of alkali and alkaline earth metallic species on the steam gasification of sawdust biochar in a lab-scale, fixed-bed reactor, with the method of chemical fractionation analysis [14]. The results indicated that $\mathrm{H}_{2} \mathrm{O} / \mathrm{NH}_{4} \mathrm{Ac} / \mathrm{HCl}$-soluble AAEMs have a significant effect on biochar gasification rates. The release of $\mathrm{K}$ occurs mainly in the form of inorganic salts and hydrated ions, while that of $\mathrm{Ca}$ occurs mainly as organic ones. The $\mathrm{sp}^{3}$-rich or $\mathrm{sp}^{2}$-sp $\mathrm{s}^{3}$ structures and different chemical-speciation AAEMs function together as the preferred active sites during steam gasification. $\mathrm{H}_{2} \mathrm{O} / \mathrm{HCl}$-soluble AAEMs could promote the transformation of biochar surface functional groups, from ether/alkene C-O-C to carboxylate $\mathrm{COO}$ - in biochar, while they may both be improved by $\mathrm{NH}_{4}$ Ac-soluble AAEMs $\mathrm{H}_{2} \mathrm{O}$-soluble AAEMs play a crucial catalytic role in biochar reactivity.

In addition to the inorganic elements, char preparation methods may influence the gasification reactivity. Dahou et al. conducted a study to investigate the parameters that influence the steam gasification kinetics according to the biomass type and char preparation method [15]. Chars were prepared using three different sets of low heating rate (LHR) pyrolysis conditions including different temperatures and biomass bed geometry. The authors have shown by a characteristic time analysis that these pyrolysis conditions were not associated with a chemical regime in a large amount of devices. However, they have shown that conditions used to prepare the char had a much lower influence on steam gasification kinetics than the biomass type.

The presence of heavy metals in waste wood may have negative effects during the gasification process through toxicity emissions and facility damaging. Therefore, Al-Badri et al. have performed thermodynamic equilibrium calculations for the Boudouard reaction (BR) and partial combustion reaction (PCR) to explore the possible interactions and interferences among CCA-elements themselves and with $\mathrm{Ca}, \mathrm{Na}, \mathrm{S}, \mathrm{Cl}, \mathrm{Fe}$, and $\mathrm{Ni}$ during the gasification of contaminated waste wood [16]. The results revealed that $\mathrm{Ni}$-As interactions generate dominant species $\mathrm{As}_{2} \mathrm{Ni}_{5}$ and $\mathrm{As}_{8} \mathrm{Ni}_{11}$, which increase the solid-gaseous transformation temperature of As. Moreover, the interactions between $\mathrm{Ca}$ and $\mathrm{Cr}$ predominantly form $\mathrm{C}_{3} \mathrm{Cr}_{7}$; whereas the absence of Ca leads to $\mathrm{Cr}_{2} \mathrm{Na}_{2} \mathrm{O}_{4}$ causing instability in the $\mathrm{Cr}$ phase transformation.

During the char gasification, an ash layer is accumulated on the char surface. The ash layer increases the mass transfer resistance of $\mathrm{O}_{2}$ to the gasification surface, which may become the limiting step of whole process. In this context, Lin et al. studied $\mathrm{O}_{2}$ diffusion in the ash layer formed on cylindrical char samples using a specially designed one-dimension setup in a thermogravimetric apparatus (TGA) [17]. The effective internal diffusion coefficient $\left(D_{e}\right)$ was found to increase with an increase in ash layer thickness, due to an increase in median pore diameter. Methods were established to correlate $D_{e}$ with operating conditions and to estimate the role of internal diffusion resistance in overall mass transfer resistance.

The effect of ash melting phenomena was also assessed by Kim et al. through the development of a one-dimensional (1-D) entrained-flow gasifier model [18]. The authors have included sensible heat of slag and the fusion heat of ash in the heat balance equation in their model. To consider the melting of ash, they have proposed an algorithm that calculates the energy balance for three scenarios based on temperature. Based on the Texaco pilot plant gasifier, the model was validated. The obtained results showed good agreement with previous experimental data. Kim et al. have concluded that the sensible heat of slag and the fusion heat of ash must be included in the entrained flow gasifier model.

In addition to the thermal conversion, biomass chars could be physically or chemically activated in order to elaborate efficient adsorbents. In this sense, Abdeljaoued et al. have produced an activated 
carbon from coconut shells with suitable characteristics to separate $\mathrm{CO}_{2}$ from biogas [19]. The textural characterization of the adsorbent has been determined. Pure component adsorption isotherms of $\mathrm{CO}_{2}$ and $\mathrm{CH}_{4}$ at $30-70{ }^{\circ} \mathrm{C}$ have been measured. The obtained results revealed that the activated carbon had high $\mathrm{CO}_{2}$ adsorption capacity. Equilibrium of adsorption of $\mathrm{CO}_{2}$ and $\mathrm{CH}_{4}$ adsorption on the produced activated carbon reached $8.36 \mathrm{mmol} / \mathrm{g}$ and $4.63 \mathrm{mmol} / \mathrm{g}$, respectively, at $30^{\circ} \mathrm{C}$ and $10 \mathrm{bar}$.

Peredo-Mancilla et al. have compared the performance of different biomass-based activated carbons for $\mathrm{CO}_{2}$ and $\mathrm{CH}_{4}$ adsorption [20]. In particular, authors have studied the influence of the activation method on the adsorption uptake using three activated carbons obtained by different activation methods $\left(\mathrm{H}_{3} \mathrm{PO}_{4}\right.$ chemical activation and $\mathrm{H}_{2} \mathrm{O}$ and $\mathrm{CO}_{2}$ physical activation) of olive stones. For the three adsorbents, the $\mathrm{CO}_{2}$ adsorption was more important than that of $\mathrm{CH}_{4}$. The chemically-activated carbon presented a higher specific surface area and micropore volume, which led to a higher adsorption capacity of both $\mathrm{CO}_{2}$ and $\mathrm{CH}_{4}$. For methane adsorption, the presence of mesopores facilitated the diffusion of the gas molecules into the micropores. In the case of carbon dioxide adsorption, the presence of more oxygen groups on the water vapor-activated carbon enhanced its adsorption capacity.

Energy crops such as Miscanthus have attracted growing interest during the last decade. Saletnik et al. have assessed the possibility of using biochar and ash from plant biomass to fertilise giant miscanthus (Miscanthus $x$ giganteus). Authors have examined the optimisation of the combination of fertiliser applications of the aforementioned materials in the context of the plant yield obtained. There was an increase in yield of $8-68 \%$ over the two years of research when compared with the control plots. It was found that the application of biochar, ash from biomass and a combination of the two at appropriate rates as a soil additive can substitute for classic mineral fertilisers and strengthen the ecological aspects of energy crop cultivation.

We found the edition and selections of papers for this Special Issue very inspiring and rewarding. We also thank the editorial staff and reviewers for their efforts and help during the process.

\section{References}

1. Moulogianni, C.; Bournaris, T. Biomass Production from Crops Residues: Ranking of Agro-Energy Regions. Energies 2017, 10, 1061. [CrossRef]

2. Khiari, B.; Jeguirim, M. Pyrolysis of Grape Marc from Tunisian Wine Industry: Feedstock Characterization, Thermal Degradation and Kinetic Analysis. Energies 2018, 11, 730. [CrossRef]

3. Lee, Y.; Jo, J.; Kim, I.; Yoo, Y. Value-Added Performance and Thermal Decomposition Characteristics of Dumped Food Waste Compost by Pyrolysis. Energies 2018, 11, 1061. [CrossRef]

4. Liu, X.; Luo, Z.; Yu, C.; Jin, B.; Tu, H. Release Mechanism of Fuel-N into NOx and $\mathrm{N}_{2} \mathrm{O}$ Precursors during Pyrolysis of Rice Straw. Energies 2018, 11, 520. [CrossRef]

5. Oh, S.; Yoon, Y. Energy Recovery Efficiency of Poultry Slaughterhouse Sludge Cake by Hydrothermal Carbonization. Energies 2017, 10, 1876. [CrossRef]

6. Liu, C.; Huang, X.; Kong, L. Efficient Low Temperature Hydrothermal Carbonization of Chinese Reed for Biochar with High Energy Density. Energies 2017, 10, 2094. [CrossRef]

7. Dieguez-Alonso, A.; Funke, A.; Anca-Couce, A.; Rombolà, A.; Ojeda, G.; Bachmann, J.; Behrendt, F. Towards Biochar and Hydrochar Engineering-Influence of Process Conditions on Surface Physical and Chemical Properties, Thermal Stability, Nutrient Availability, Toxicity and Wettability. Energies 2018, 11, 496. [CrossRef]

8. Lee, Y.; Jo, J.; Kim, I.; Yoo, Y. Chemical Characteristics and $\mathrm{NaCl}$ Component Behavior of Biochar Derived from the Salty Food Waste by Water Flushing. Energies 2017, 10, 1555. [CrossRef]

9. Lee, Y.; Jo, J.; Kim, I.; Yoo, Y. Influence of $\mathrm{NaCl}$ Concentration on Food-Waste Biochar Structure and Templating Effects. Energies 2018, 11, 2341. [CrossRef]

10. Boukaous, N.; Abdelouahed, L.; Chikhi, M.; Meniai, A.; Mohabeer, C.; Bechara, T. Combustion of Flax Shives, Beech Wood, Pure Woody Pseudo-Components and Their Chars: A Thermal and Kinetic Study. Energies 2018, 11, 2146. [CrossRef] 
11. Mami, M.; Mätzing, H.; Gehrmann, H.; Stapf, D.; Bolduan, R.; Lajili, M. Investigation of the Olive Mill Solid Wastes Pellets Combustion in a Counter-Current Fixed Bed Reactor. Energies 2018, 11, 1965. [CrossRef]

12. Kim, G.; Kim, J.; Lisandy, K.; Jeon, C. Experimental Model Development of Oxygen-Enriched Combustion Kinetics on Porous Coal Char and Non-Porous Graphite. Energies 2017, 10, 1436. [CrossRef]

13. Liu, X.; Wei, J.; Huo, W.; Yu, G. Gasification under $\mathrm{CO}_{2}-$ Steam Mixture: Kinetic Model Study Based on Shared Active Sites. Energies 2017, 10, 1890. [CrossRef]

14. Feng, D.; Zhao, Y.; Zhang, Y.; Sun, S.; Gao, J. Steam Gasification of Sawdust Biochar Influenced by Chemical Speciation of Alkali and Alkaline Earth Metallic Species. Energies 2018, 11, 205. [CrossRef]

15. Dahou, T.; Defoort, F.; Thiéry, S.; Grateau, M.; Campargue, M.; Bennici, S.; Jeguirim, M.; Dupont, C. The Influence of Char Preparation and Biomass Type on Char Steam Gasification Kinetics. Energies 2018, 11, 2126. [CrossRef]

16. Al-Badri, S.; Jiang, Y.; Wagland, S. Possible Interactions and Interferences of Copper, Chromium, and Arsenic during the Gasification of Contaminated Waste Wood. Energies 2018, 11, 1966. [CrossRef]

17. Lin, X.; Liu, Q.; Liu, Z. Estimation of Effective Diffusion Coefficient of $\mathrm{O}_{2}$ in Ash Layer in Underground Coal Gasification by Thermogravimetric Apparatus. Energies 2018, 11, 460. [CrossRef]

18. Kim, J.; Oh, H.; Lee, S.; Yoon, Y. Advanced One-Dimensional Entrained-Flow Gasifier Model Considering Melting Phenomenon of Ash. Energies 2018, 11, 1015. [CrossRef]

19. Abdeljaoued, A.; Querejeta, N.; Durán, I.; Álvarez-Gutiérrez, N.; Pevida, C.; Chahbani, M. Preparation and Evaluation of a Coconut Shell-Based Activated Carbon for $\mathrm{CO}_{2} / \mathrm{CH}_{4}$ Separation. Energies 2018, 11, 1748. [CrossRef]

20. Peredo-Mancilla, D.; Ghouma, I.; Hort, C.; Matei Ghimbeu, C.; Jeguirim, M.; Bessieres, D. $\mathrm{CO}_{2}$ and $\mathrm{CH}_{4}$ Adsorption Behavior of Biomass-Based Activated Carbons. Energies 2018, 11, 3136. [CrossRef]

21. Saletnik, B.; Zagula, G.; Bajcar, M.; Czernicka, M.; Puchalski, C. Biochar and Biomass Ash as a Soil Ameliorant: The Effect on Selected Soil Properties and Yield of Giant Miscanthus (Miscanthus x giganteus). Energies 2018, 11, 2535. [CrossRef] 